


\section{A TEMPERATURE PROBE FOR RADIO-FREQUENCY HEATED MATERIAL}

Ronald R. Bowman

Electromagnetic Fields Division National Engineering Laboratory National Bureau of Standards Boulder, Colorado 80303

January 1981

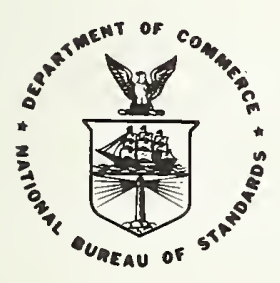

U.S. DEPARTMENT OF COMMERCE, Philip M. Klutznick, Secretary Jordan J. Baruch, Assistant Secretary for Productivity, Technology and Innovation NATIONAL BUREAU OF STANDARDS, Ernest Ambler, Director 



\section{CONTENTS}

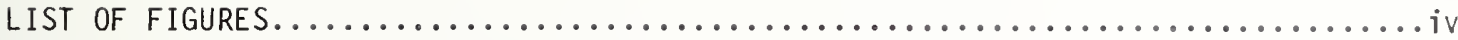

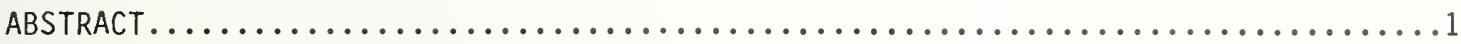

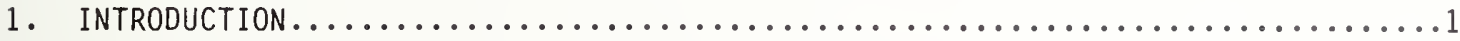

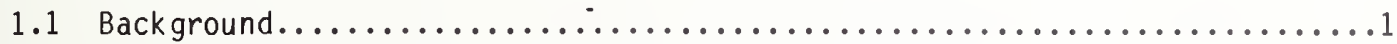

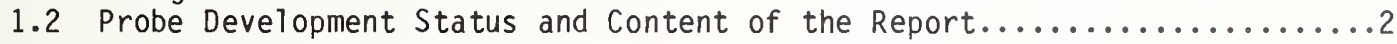

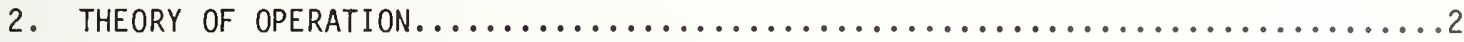

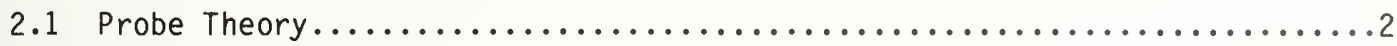

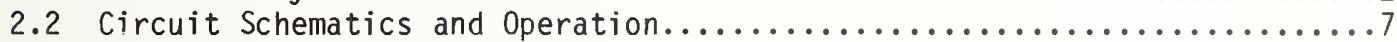

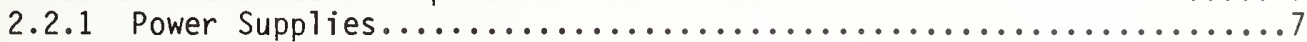

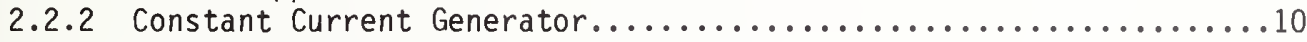

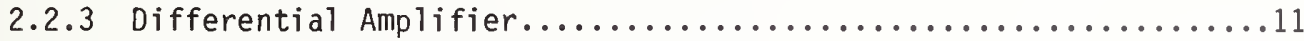

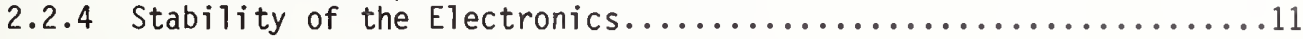

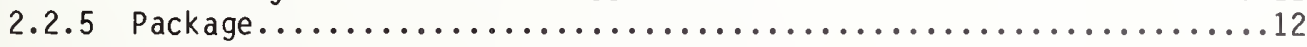

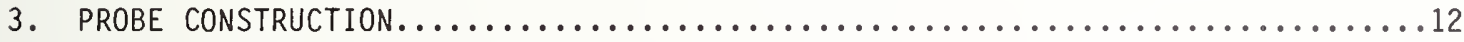

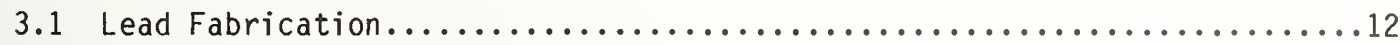

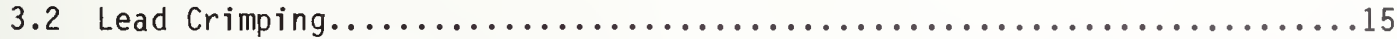

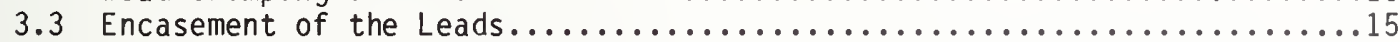

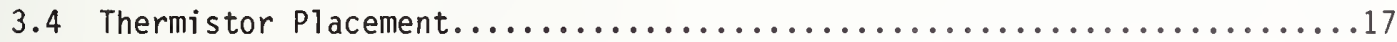

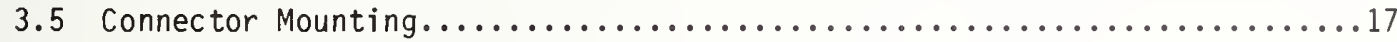

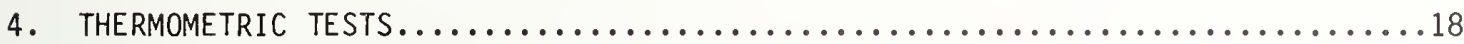

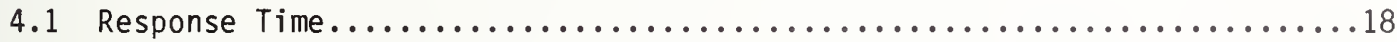

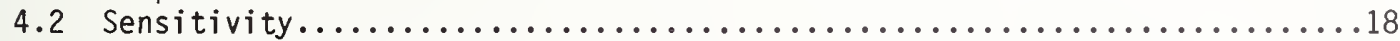

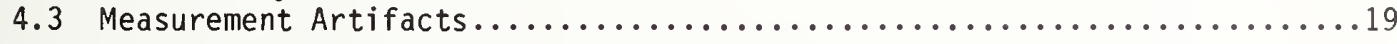

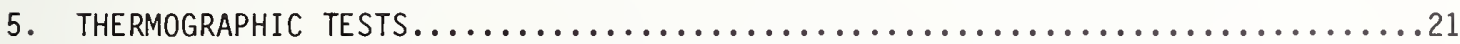

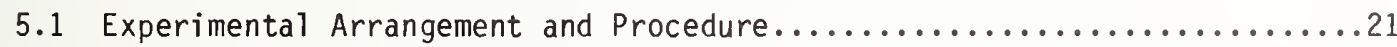

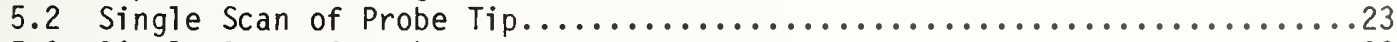

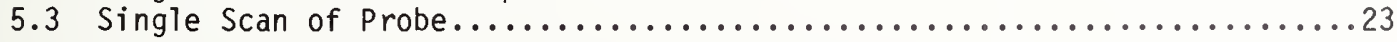

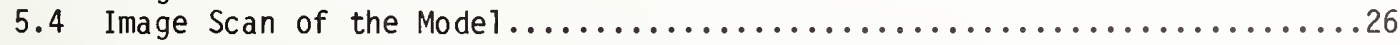

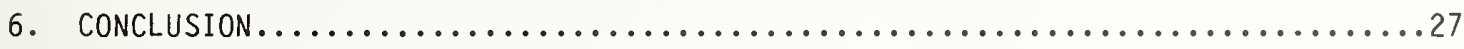

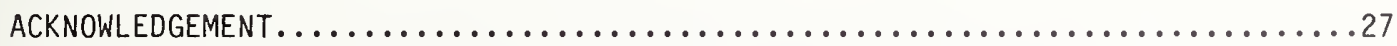

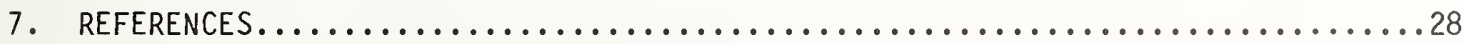




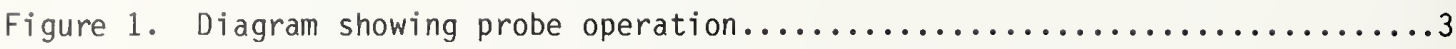

Figure 2. Simple model of the probe at points far from the tip.............

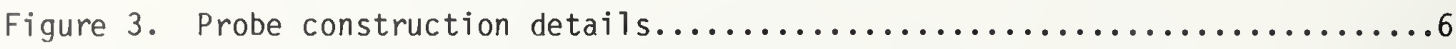

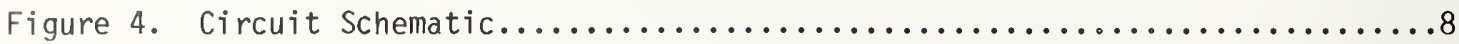

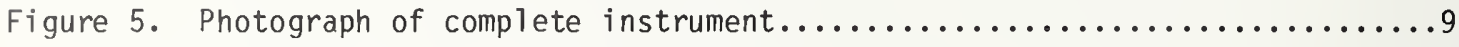

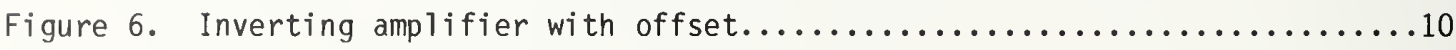

Figure 7. (a) Construction details of laminar sheet

(b) Cross-section of high-resistance twin-lead cut from the

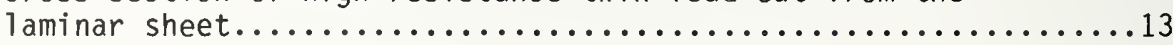

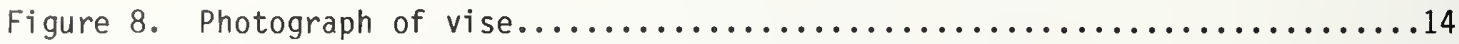

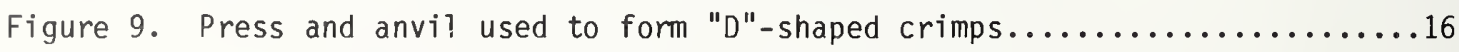

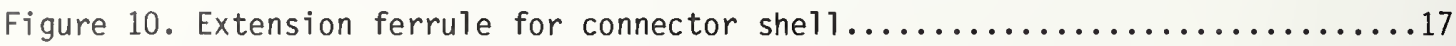

Figure 11. Theoretical response for a probe with a one second time constant to a one degree per second heating rate starting at

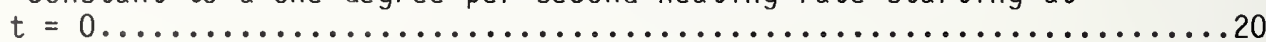

Figure 12. Model exposure arrangement for data of figure 13. The electric field polarization in the waveguide is parallel to the probe........22

Figure 13. Curve 1 shows the response of the probe in the experimental arrangement of figure 12 to an initiation of RF heating. Curve 2 (RF off) shows the noise level for this experimental

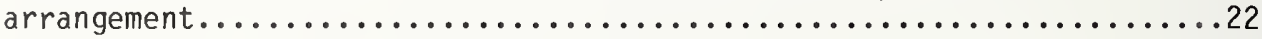

Figure 14. Experimental arrangement used for the thermographic recordings.......23

Figure 15. (a) Diagram showing model exposure geometry and thermographic scan line

(b) Resulting thermographs. The position of the probe tip is indicated by the white arrow in the left-hand thermograph. The probe was removed for the right-hand thermograph..........24

Figure 16. (a) Diagram showing model exposure geometry and thermographic scan line

(b) The position of the probe tip is indicated by the white arrow in the left-hand thermograph. The probe was removed for the

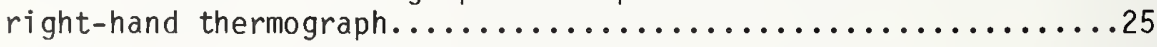

Figure 17. Thermographic images of the model resulting from the exposure geometry shown in figure 16. The position of the probe tip is indicated by the black arrows in the left-hand image. The probe was removed for recording the right-hand image.................... 


\section{A TEMPERATURE PROBE FOR RADIO-FREQUENCY HEATED MATERIAL}

Ronald R. Bowman

One approach to measuring temperature in radio-frequency ( $r f$ ) heated material employs thermocouple or thermistor sensors connected to suitable electronics by means of leads of such slight conductivity that they cause negligible field distortion and measurement artifacts. The particular type of probe discussed here uses a thermistor. Four leads are used to allow the thermistor resistance to be sensed despite the large and unstable lead resistances. Though difficult to construct, small probes (about $1.1 \mathrm{~mm}$ in diameter) for use in biological tissue can be made that cause measurement artifacts so slight (about $0.01{ }^{\circ} \mathrm{C}$ or 1 ess) that they are difficult to measure. Theory and experimental results are presented to show that these probes are very effective for use in materials with high water content. In most situations of interest, the short term stability is better than $0.01^{\circ} \mathrm{C}$ and the long term stability is about $0.1^{\circ} \mathrm{C}$.

Key words: Heating; probe; radio-frequency; temperature measurements.

\section{INTRODUCTION}

\subsection{Background}

For electromagnetic bioeffects research, therapy by electrohyperthermia, and control of potentially hazardous fields, it is important to be able to measure temperature in subjects and models being exposed to intense radio-frequency ( $r f$ ) fields. Similar needs exist for various industrial processes using rf heating. Except in special circumstances, conventional thermocouple or thermistor probes cannot be used for these measurements due to the severe field distortions caused by the metallic leads of these devices. In particular, intense heating is caused at the tip of the probe where the leads terminate. This heating causes large measurement artifacts $[6,9]$ and sometimes damage of the surrounding material. Until recently, this measurement problem had no satisfactory solution. Since 1974, several temperature probes have been developed using light transmission through optical fibers to interrogate various types of temperature sensitive transducers $[1,2,3,4]$.

Another probe being developed is based on pressure change due to the temperature dependence of viscosity of a fluid forced through a small orifice at the tip [5]. The subject of the discussion here is an example of a third approach that employs thermocouple or thermistor temperature sensors that are connected to suitable electronics by means of leads of very low conductivity so that they cause negligible field distortion and measurement artifacts $[6,9]$.

A11 of the above probes are undergoing rapid development, and it is difficult to predict 
which of them eventually will be most effective. It is likely that no single type of probe will be best suited to a11 measurement tasks. The probe discussed in this report was developed primarily for use in relatively lossy substances, such as animal tissue or any substance with high water content, and it works very well for this type of application. When applicable, this probe allows the well-known virtues of the thermistor (sensitivity, stability, relatively simple electronics, few calibration points required to define response curve) to be available for temperature measurements in rf-heated materials.

\subsection{Probe Development Status and Content of the Report}

The goals of the work reported here were to construct and test a prototype probe and the electronics to prove feasibility and illustrate the characteristics of this type of temperature-measuring device. These goals have been achieved, and no further work is planned.

In addition to the probe and electronics theory, the basic probe construction techniques and circuit schematics are discussed herein. The experimental results reported include both the performance of the probe as an ordinary thermometer (e.g., response time and sensitivity) and measurements of the small artifacts occurring when it is used in rf-heated material with high water content.

\section{THEORY OF OPERATION}

\subsection{Probe Theory}

As shown in figure 1 , the probe consists simply of two pairs of high resistance leads connected to a small thermistor. The thermistor resistance is sensed by injecting a constant current through one pair of leads and measuring the voltage developed across the thermistor by means of a high-impedance amplifier connected to the other pair. 1 If the current generator and amplifier have sufficiently high impedance compared to the leads, the thermistor resistance can be accurately sensed despite the large and unstable lead resistances. This technique is commonly used for resistance measurements when the lead resistance is significant, but in the present application the lead resistances will be very large, on the order of $10 \mathrm{Mr}$.

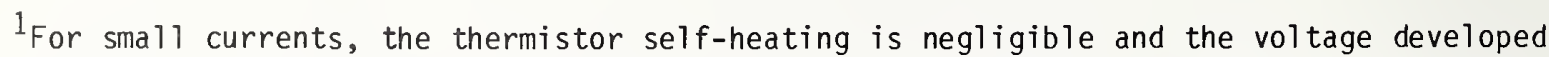
acrossd the thermistor is proportional to the current through it. Therefore, it is not necessary to have constant current if the current is measured rather than regulated to a known value. Both alternatives are easily implemented to achieve an electronic readout of the thermistor resistance (or some derived signal such as a linearized readout directly in degrees).
} 
Because of the large lead resistances, it is necessary to use small currents to drive the probe, otherwise: (a) Significant heat will be generated in the leads and the thermistor, and (b) large voltages will be required to inject the probe current. Then, to obtain good sensitivity, the thermistor must have a high resistance. Small, thin thermistors (called "flake" thermistors) are commercially available with resistances of about $1 \mathrm{M}$ at $25^{\circ} \mathrm{C}$ and coefficients of about -0.04 per ${ }^{\circ} \mathrm{C}$. Though somewhat higher thermistor resistances of several megohms would be desirable, they were not available and the 1 Ma flake thermistors were used with good results.

Of major importance for the design of the probe and electronics is the nominal lineal resistance value of the thermistor leads. The resistance per unit length must be 1 arge enough to achieve an essentially nonperturbing and artifact-free probe but must be kept as small as possible to minimize the demands on the electronics and limit the "static" noise problems. The probe structure is complicated enough that a reasonably accurate electrothermodynamic analysis would be difficult, and no attempt was made to accurately calculate the required lineal resistance of the lead material. However, the following approximate analysis allows an estimate of the required resistance.

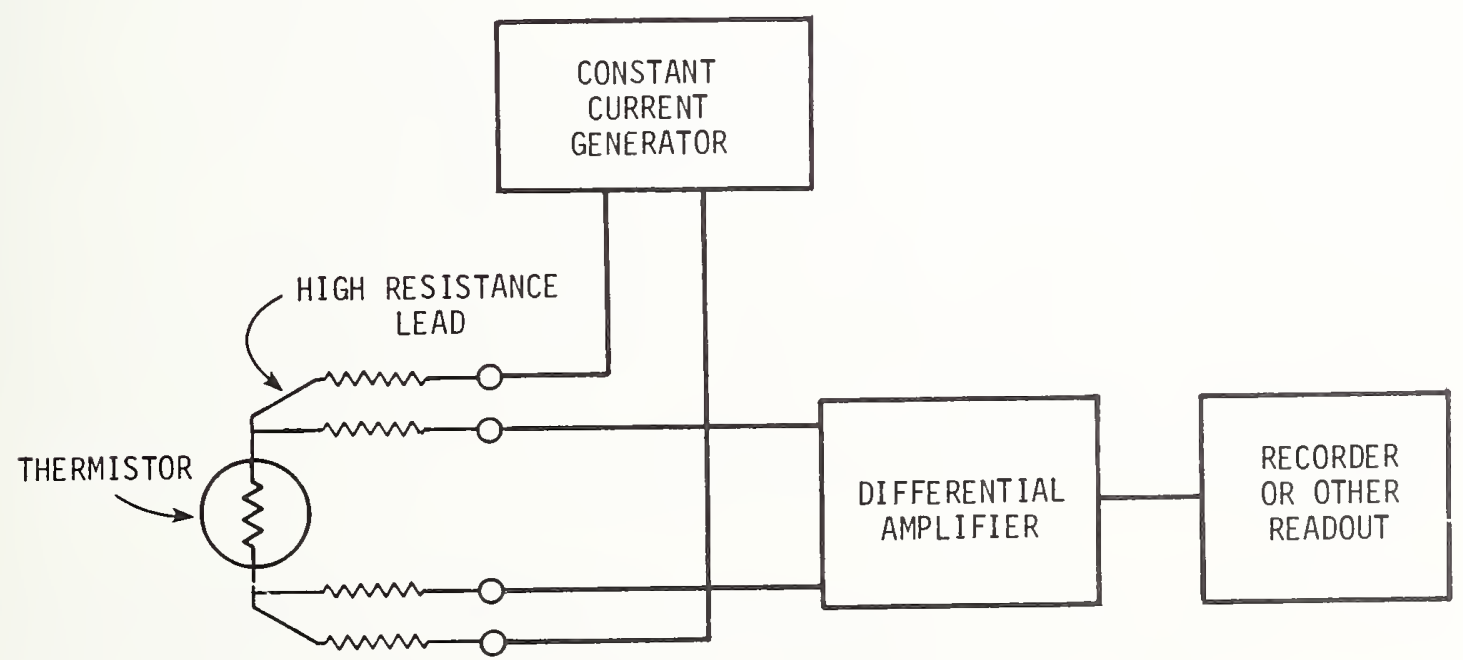

Figure 1. Diagram showing probe operation. 
Figure 2 shows a highly simplified model of the probe at a point far from the tip. In this model, only one concentric conductor is within the sheath, the probe extends indefinitely along its axis, all materials are nonmagnetic, the conductor material has the same order of conductivity as the surrounding medium, the sheath material is nonconductive, and the radi $\mathrm{a}$ and $\mathrm{b}$ are small compared to the characteristic wavelengths in the conductor and medium. With the electric field parallel to the probe (which will give maximum heating within the conductor), these conditions, plus the condition that the parallel component of the electric field is continuous across a boundary, assure that the electric-field magnitude $E$ will be approximately uniform throughout the medium and probe. Then, since the heating in any conductive material is given by $\sigma E^{2}$ where $\sigma$ is the conductivity of the material, the total heating per unit length within the probe is approximately

$$
\sigma_{C} E^{2} \int_{0}^{a}(2 \pi r) d x=\sigma_{c} E^{2} A_{C} \text {, }
$$

where $\sigma_{c}$ is the conductivity and $A_{C}$ is the cross-sectional area of the conductor. This is the same heating that would occur in a probe of diameter $b$ with uniform conductivity $\sigma_{a}=\left(A_{c} / A_{t}\right)_{\sigma}$ where $A_{c} / A_{t}$ is the ratio of the conductor cross-section to the total cross section. Therefore, the worst-case probe heating for the model will be less than the heating that would occur in the material displaced by the probe if $\sigma_{c}<\left(A_{t} / A_{c}\right) \sigma_{m}$, where $\sigma_{m}$ is the conductivity of the material surrounding the probe.

Except at the tip, the heating in the probe will be roughly the same as for the model if $A_{C}$ is the sum of the cross-sectional area of the four conductors. From figure 3 it follows that $A_{c} / A_{t}$ is about 15. Therefore, if the probe is in muscle tissue (o above $100 \mathrm{MHz}$ typically $>1 \mathrm{~S} / \mathrm{m}[8,10])$, the conductor material could probably have a $\sigma$ as high as about $15 \mathrm{~S} / \mathrm{m}$ without causing excess heating. The conductor material used has a $\sigma$ of about $4 \mathrm{~S} / \mathrm{m}^{2}{ }^{2}$ which means that the probe should appear cool in all tissues except those with low water content (such as bone or fat with $\sigma$ typically > $0.05 \mathrm{~S} / \mathrm{m}$ above $100 \mathrm{MHz}[8,10]$ ). In these tissues, the probe would probably, with parallel E orientation, appear warm. However, due to the small diameter of the probe, considerable excess heating is required to cause substantial temperature rises in the surrounding material.

The tip of the probe is difficult to model in a reasonable way. Because the crimps are much more conductive than the leads and the thermistor material is much less conductive than the leads, some insight might be gained by modeling the probe tip as a metallic sphere or cylinder thickly coated with nonlossy dielectric; but no attempt was made to quantitatively analyze this type of model. The author believes that the well-known intense heating due to

${ }^{2}$ Resulting in a lineal lead resistance of about $160 \mathrm{~K} \Omega / \mathrm{cm}$. 


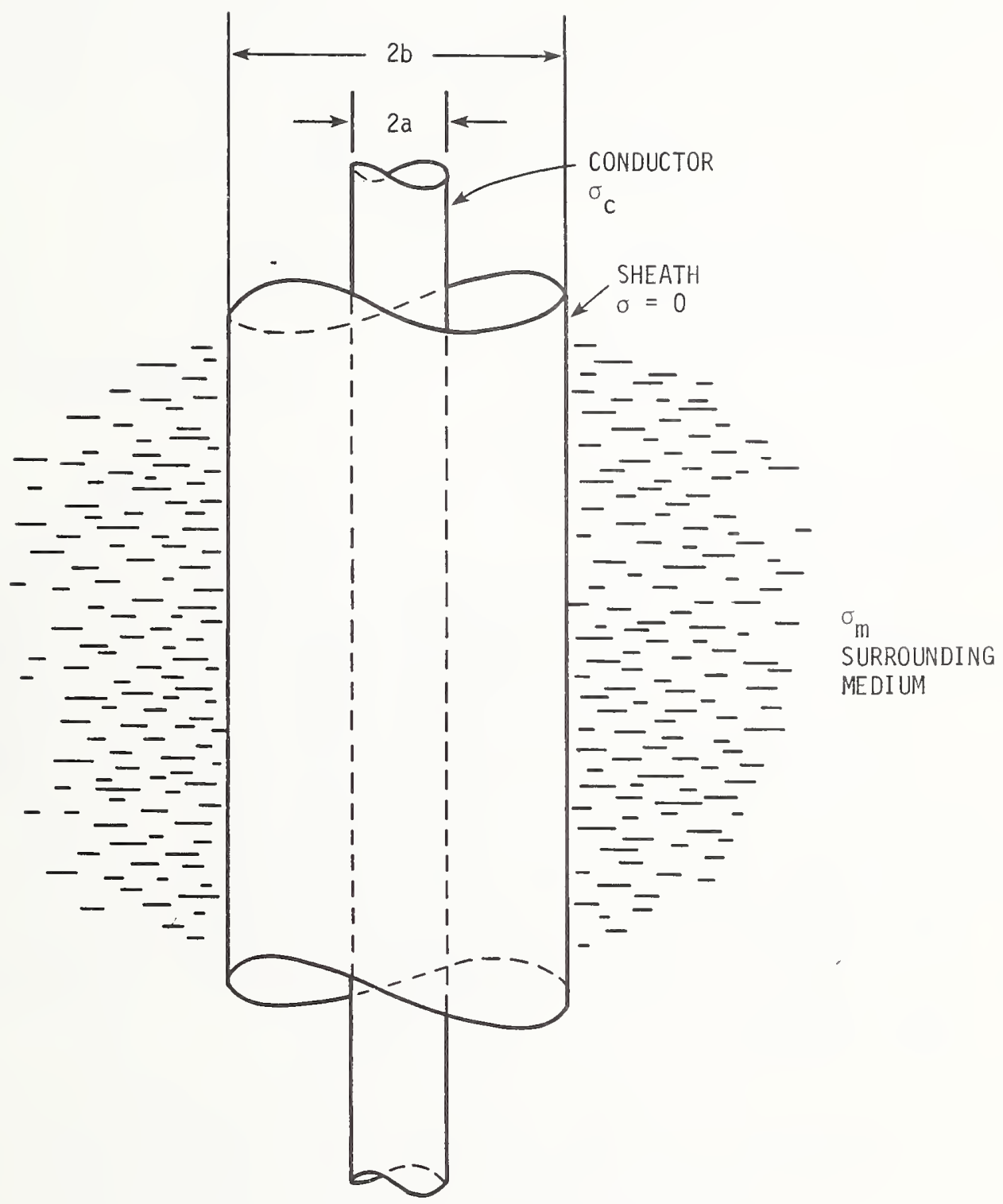

Figure 2. Simple model of the probe at points far from the tip. 


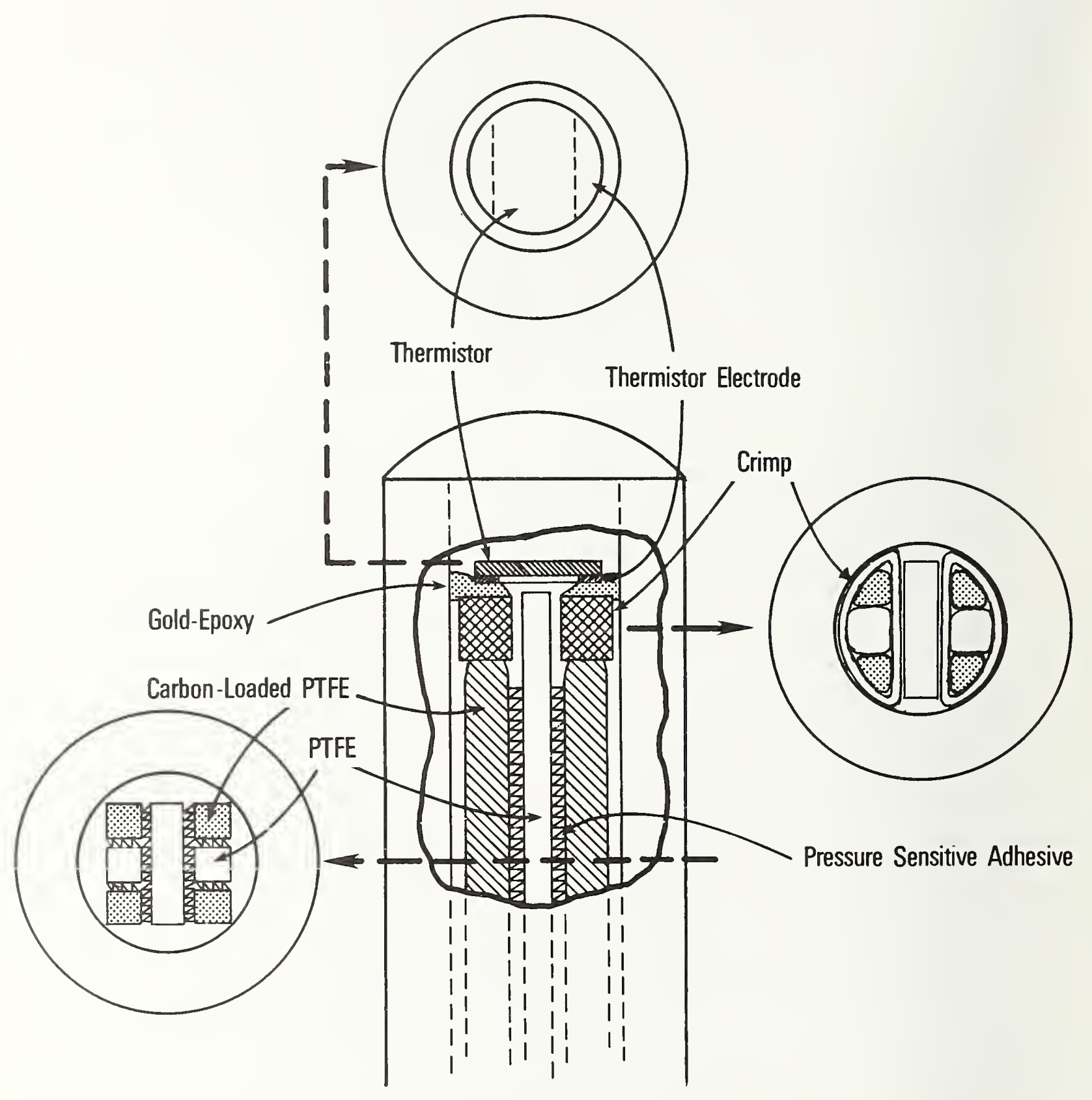

Figure 3. Probe construction details. 
field enhancements at the tip of uninsulated thin electrodes placed in biological materials will not occur for the insulated probe discussed here because: (1) Currents flowing on the leads will tend to drop to zero at the tip (except for some current flowing by way of the small capacitance of the tip with respect to material outside the sheath), and (2) field enhancements due to points and edges on the crimps and thermistor will be very local and mostly within the nonconductive sheath material. Whatever is the case, the experimental data shown later indicates that there are no substantial measurement artifacts when using the probe described here in materials with high water content.

\subsection{Circuit Schematics and Operation}

The circuit described here was designed for testing the four-wire, high-resistance type of temperature probe. The circuit works well but lacks such conveniences as a linearized output and a panel display. It is emphasized that the circuit design has not necessarily been optimized and that other circuit possibilities were not explored ${ }^{3}$.

A simplified schematic is shown in figure 4 and discussed in the next two sections. The circuit implements the straightforward technique of injecting a constant current through the thermistor and observing the voltage developed by means of a high-impedance, differential amplifier. The current I is, essentially, $I=1.25 /\left[3\left(10^{-6}\right)\right]$; and the gain $G$ of the amplifier is set so that $G=\left(10^{-6}\right) / \mathrm{I}$. Then the output signal is scaled for 1 volt per megohm of thermistor resistance.

The actual circuit used was somewhat more complicated than that shown in figure 4 . Some test points and switches were included that were useful during the final design and evaluation of the circuit but were not needed later. This is why the electronics package shown in figure 5 has more panel switches than necessary. Only a toggle switch for turning the power on and off and a three-position rotary switch are needed for the circuit as discussed here, and the other switch functions will be ignored.

\subsubsection{Power Supplies}

The circuits operate from $+5 V$ and $-5 V$ supplies generated from two 9-V batteries. The plus supply is provided by a three-terminal regulator. In figure 4 , the regulator holds a constant $1.25 \mathrm{~V}$ (nominal) between the two points indicated. Then $R_{3}$ sets a fixed current, essentially all of which passes through $R_{4}$. By choosing $R_{3}$ and $R_{4}$, the desired supply voltage results. (The current through $R_{3}$ must be about $1 \mathrm{~mA}$ or more for the regulator to

${ }^{3}$ Certain commercial materials are identified in this paper in order to present an adequate discussion of the electronic circuits. In no case does such identification imply recommendation or endorsement by the National Bureau of Standards, nor does it imply that the material is necessariy the best available for the purpose. 


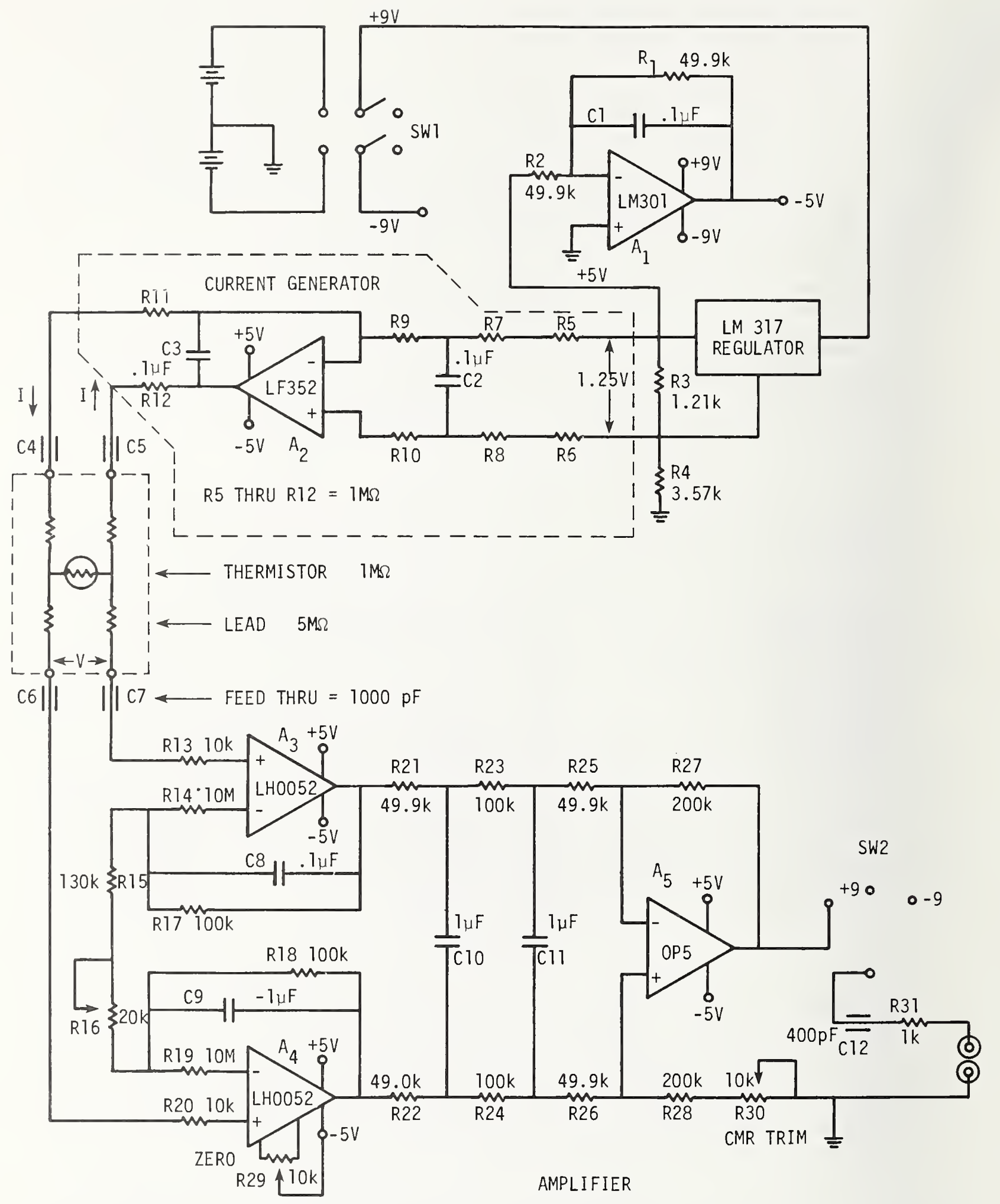

Figure 4. Circuit Schematic. 


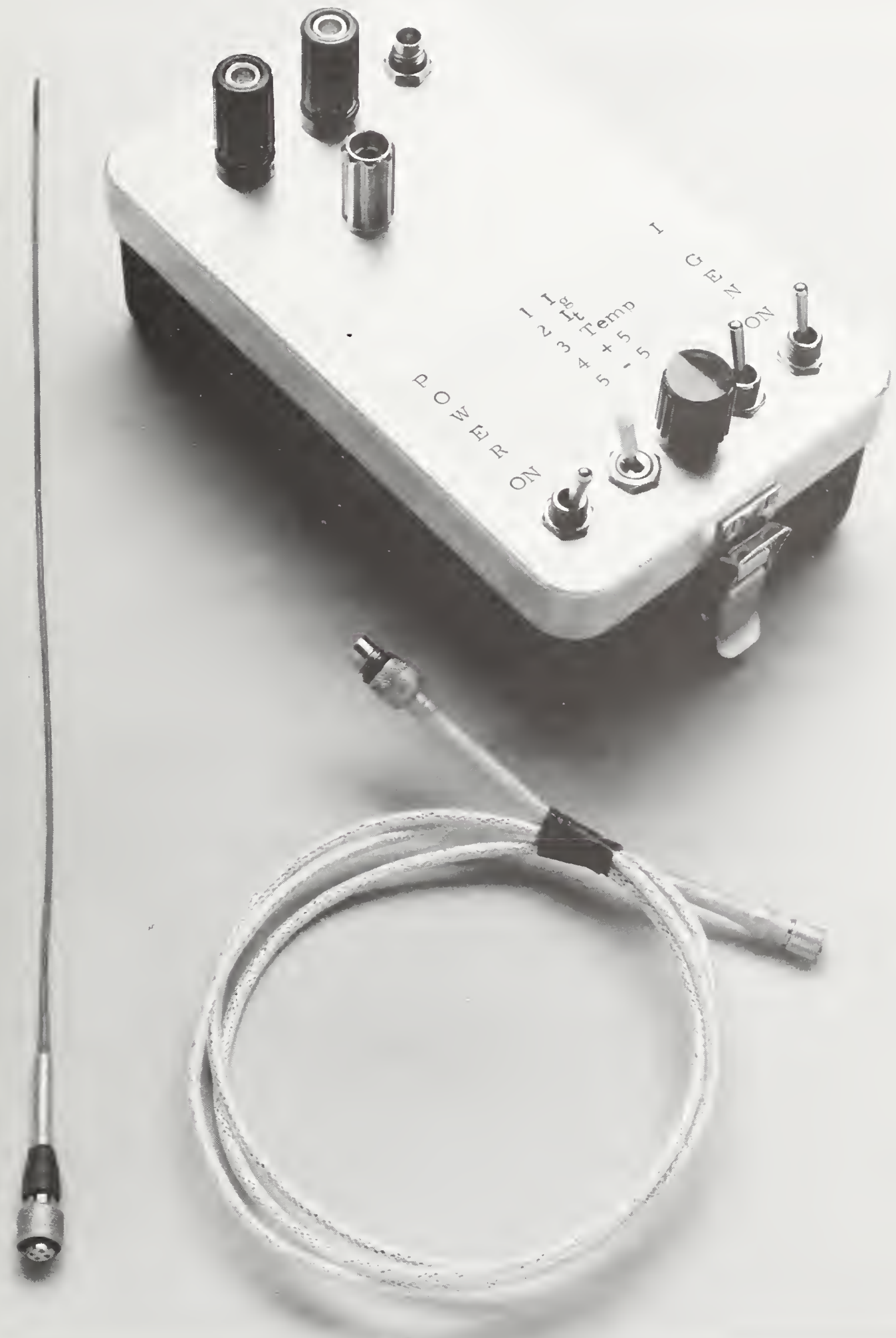

Figure 5. Photograph of complete instrument. 
function properly.)

The minus supply is provided by an inverting amplifier $\left(A_{1}\right)$ with a gain of one and operating from the $9-V$ batteries

\subsubsection{Constant Current Generator}

The constant current generator was designed so that the common-mode voltage on the leads to the amplifier would be roughly at the power supply common. This is easily accomplished using the elevated $1.25-\mathrm{V}$ reference provided by the regulator. To see how this is done, refer to figure 6 . Assuming the operational amplifier to be perfect, no current flows into either amplifier input terminal and both input terminals are at the same voltage $e_{2}$. Then

$$
\frac{e_{1}-e_{2}}{R_{i}}=\frac{e_{2}-e_{0}}{R_{f}}
$$

and

$$
e_{0}=e_{2}-\left(e_{1}-e_{2}\right) \frac{R_{f}}{R_{j}} .
$$

Now, if we wish the midpoint of $R_{f}$ to be at "ground" potential, e $e_{0}$ must equal $-e_{2}$. Therefore,

$$
e_{2}=\left(\frac{e_{1}-e_{2}}{2}\right) \frac{R_{f}}{R_{i}}
$$

For the design shown in figure $4, R_{f}$ is approximately $15 \mathrm{M}$, the differential voltage is

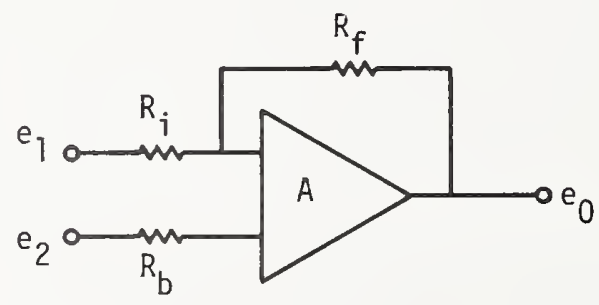

Figure 6. Inverting amplifier with offset. 
1.25 , and $e_{2}$ is about $3.75 \mathrm{~V}$. Then, $R_{i}$ must be about $2.5 \mathrm{Mr}$. $R_{j}$, the sum of $R_{5}, R_{7}$, and $R_{9}$, was chosen to be the convenient value of $3 \mathrm{M}$, which is sufficiently close to the "optimum" value. The residual common-mode voltage is rejected by the differential amplifier. Resistors $R_{6}, R_{8}$, and $R_{10}$ are used to balance the drifts due to the input currents demanded by $A_{2} \cdot C_{2}$ provides filtering but is probably not necessary.

Note that $A_{2}$ must supply a voltage within about $1.25 \mathrm{~V}$ of its minus supply. This requirement affects the choice of operational amplifier for $A_{2}$ since not al1 will meet this demand.

The current supply and return wires are filtered by feed-through capacitors to reduce the rf currents on these wires due to shield-leakage of the probe cable or "pick-up" by the probe itself.

\subsubsection{Differential Amplifier}

The differential amplifier is the well-known "instrumentation amplifier" type, as shown in the lower half of figure 4. The input operational amplifiers must have very high input impedances, very low input offset currents, and low offset voltage drift. (In addition to the choice for amplifiers $A_{3}$ and $A_{4}$ shown in figure 4 , there are a number of other commercial amplifiers with equal or better specifications.) The output operational amplifier $A_{5}$ must also have low drift since the input stage has a gain of only about 3 .

The interstage filter provides for rejection of the power-line-frequency interference that is inevitable due to the use of an unshielded, high-impedance probe. Rf interference is reduced by the feed-through capacitors on the amplifier input wires. The amplifier output lead is also filtered.

Note that the output jacks ("banana" type) can be switched to the plus and minus batteries to check their condition by means of the external readout or recorder.

\subsubsection{Stability of the Electronics}

The long-term (greater than one week) drifts of the electronics were not measured for a11 conditions. The week-long drifts, for laboratory conditions, were less than $0.01^{\circ} \mathrm{C}$.

The short-term drifts are caused largely by the input offset voltage drifts of $A_{3}$ and $A_{4}$ for the design shown in figure 4 . (Without the resistors $R_{16}$ and $R_{19}$ used to balance the effects of input offset current drifts, this would not be true.) The offset voltage drifts are about $10 \mathrm{uV} /{ }^{\circ} \mathrm{C}$ (ambient). The probe voltage sensitivity is roughly $10 \mathrm{mV} /{ }^{\circ} \mathrm{C}$ at $35^{\circ} \mathrm{C}$; therefore, a $10 \mu V$ drift corresponds to only $10^{-3}{ }^{\circ} \mathrm{C}$. 


\subsubsection{Package}

The electronics package is shown in figure 5, along with the probe and probe cable. The electronics package, as well as most of the circuitry, is a modified version of an NBSdesigned instrumentation amplifier for use in the presence of strong electromagnetic fields. As mentioned above, the inputs and output of the package are filtered by means of feed-through capacitors. These are located inside the package in a small box just below the input and output connectors.

The "cover" of the instrument, the black portion, is clamped against a metal-mesh gasket placed in a groove in the lid. The clamping force is provided by two spring-loaded toggle clamps, one of which is visible in figure 5 .

\section{PROBE CONSTRUCTION}

The probe construction sequence, detailed below, was: (1) The high-resistance leads were cut and formed into a long strip with the roughly square cross section shown in figure 3; (2) at one end of the strip, two short metal tubes were crimped around the leads to form paired leads; (3) the strip was then inserted into a piece of heat-shrink tubing, and the tubing was shrunk; (4) the tubing was trimmed about $0.5 \mathrm{~mm}$ above the crimps, and the thermistor was bonded to the crimps with conductive epoxy glue; (5) the tip of the probe was sealed with nonconductive epoxy; and (6) the connector was attached to the other end of the probe.

\subsection{Lead Fabrication}

The leads of the probe were fabricated from strips of 0.125-mm (5-mi1) carbon-loaded Polytetrafluoroethylene (PTFE) and strips of $0.125-\mathrm{mm}$ (5-mil) plain PTFE coated on both sides with pressure-sensitive adhesive. First, a laminar sheet of material was made with a cross section as shown in figure $7 \mathrm{a}$. The laminar sheet was clamped repetitively in a special vise (see figure 8), and thin slices were cut from the sheet. Each slice is essentially a high-resistance twin-lead with a cross-section as shown in figure $7 \mathrm{~b}$.

The thickness of the twin-leads was set by placing various thicknesses of single-sided tape on the base of the vise to act as shims. The vise was then placed upside down on the base, and the screws loosened. When the sheet fell by gravity against the center shim, the vise screws were tightened, and the vise was turned right-side up for cutting the slice. The cutting was done with a razor blade held at roughly a $15^{\circ}$ angle by a plastic block that was slid by hand along the top of the vise.

Without stripping the liners covering the adhesive layers, a length of the double-coated PTFE tape was placed in the vise; and slices, roughly $0.45-\mathrm{mm}$ (18 mils) wide, were cut using 


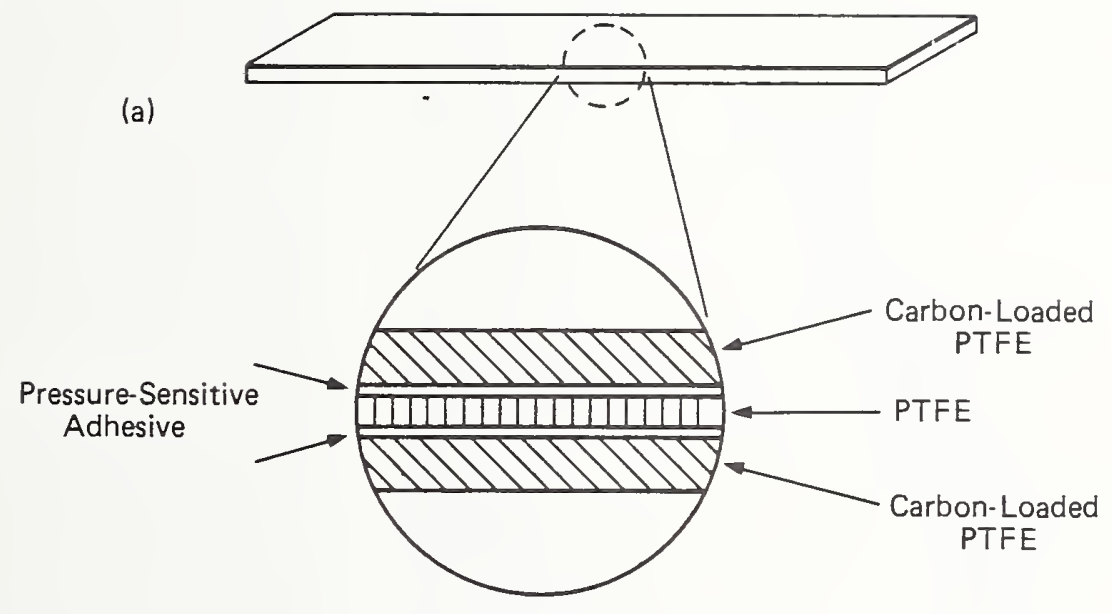

(b)

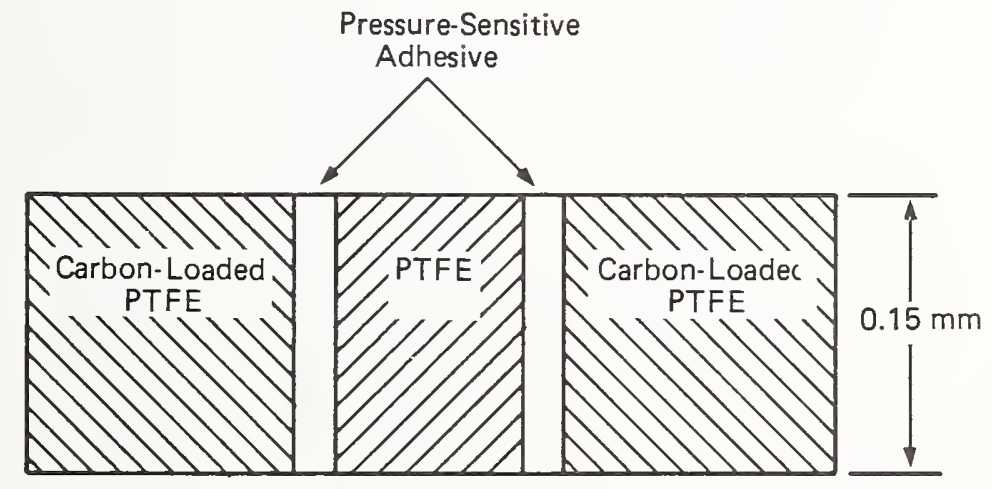

Figure 7. (a) Construction details of laminar sheet.

(b) Cross-section of high-resistance twin-lead cut from the laminar sheet. 


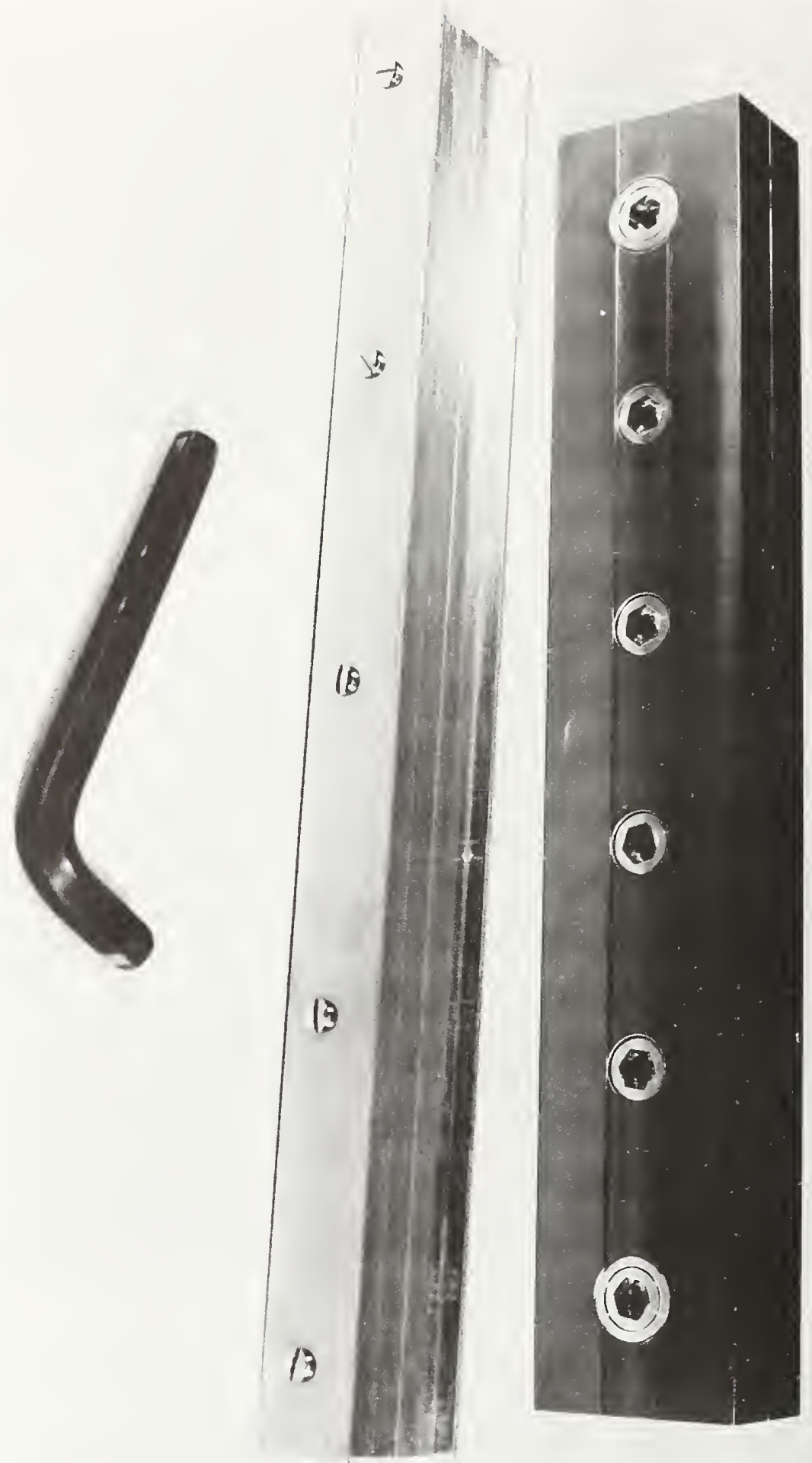

Figure 8. Photograph of vise. 
the same procedure outlined in the preceding paragraph. (The 0.45-mon width is essentially three times the $0.125-\mathrm{mm}$ PTFE sheet thickness plus $0.075-\mathrm{mm}$ to allow for the two layers of adhesive.) Using a straight edge or groove as a guide, two of the twin-leads and one of the double-coated PTFE tape slices were joined to form a "quadra-lead" with a cross section as shown in figure 3 .

\subsection{Lead Crimping}

The leads were paired at one end by crimping a small piece of metal tubing around each pair. To work properly, the tubing had to be carefully sized. By some rough calculations and experimentation, suitable dimensions for the tubing were determined to be $0.40 \mathrm{~mm}$ outside diameter and $0.32 \mathrm{~mm}$ inside diameter. Some lengths of tubing with these dimensions were made from soft stainless steel, and sections about $0.25 \mathrm{~mm}$ long were cut from the tubing, strung on a length of wire and then gold plated.

Note in figure 3 that the four leads are held together by a "wide" piece and two "narrow" pieces of double-coated tape. Each narrow piece with the adjoining two leads is a twin-lead made as described in section 3.1. The crimping operation was performed by peeling each twin-lead away from the wide tape for 3 or $4 \mathrm{~mm}$, removing about $1 \mathrm{~mm}$ of the narrow tape from the end of each twin-lead, pairing the ends of each twin-lead by slipping a crimp around them, and squeezing the crimps in a special tool (described below). The paired leads were pressed back against the wide tape and the surplus material trimmed from the end of the assembly, which was then ready for the procedure outlined in section 3.3.

As shown in figure 3, the crimps were squeezed into "D" shaped cross sections to provide a good, self-centering fit within the probe tube. This type of crimp was accomplished using a "press" and an "anvil" similar to the ones shown in figure 9. The groove in the anvil has about the same radius $(0.31 \mathrm{~mm})$ as the inside of the probe tube and subtends about $120^{\circ}$. The anvil was clamped to the base, and the press was clamped to the vertically moving part of a micromanipulator. Then, with the anvil-press gap observed with a microscope, the crimping action could be very precisely controlled.

\subsection{Encasement of the Leads}

Several types of 1.1-mm (3/64-inch), heat-shrink tubing are available with a 0.25-mm (10-mil) wall thickness (these are the shrunk dimensions). The inner diameter of the shrunk tube is then about $0.6 \mathrm{~mm}$, which is very nearly the diagonal dimension of the cross section of the quadra-lead. Polyvinylidine fluoride (PVF) heat-shrink tubing was used because it is tough and epoxy glues bond fairly well to it.

After inserting the quadra-lead into the unshrunk tube, the tube was shrunk using an ordinary hot-air gun. 


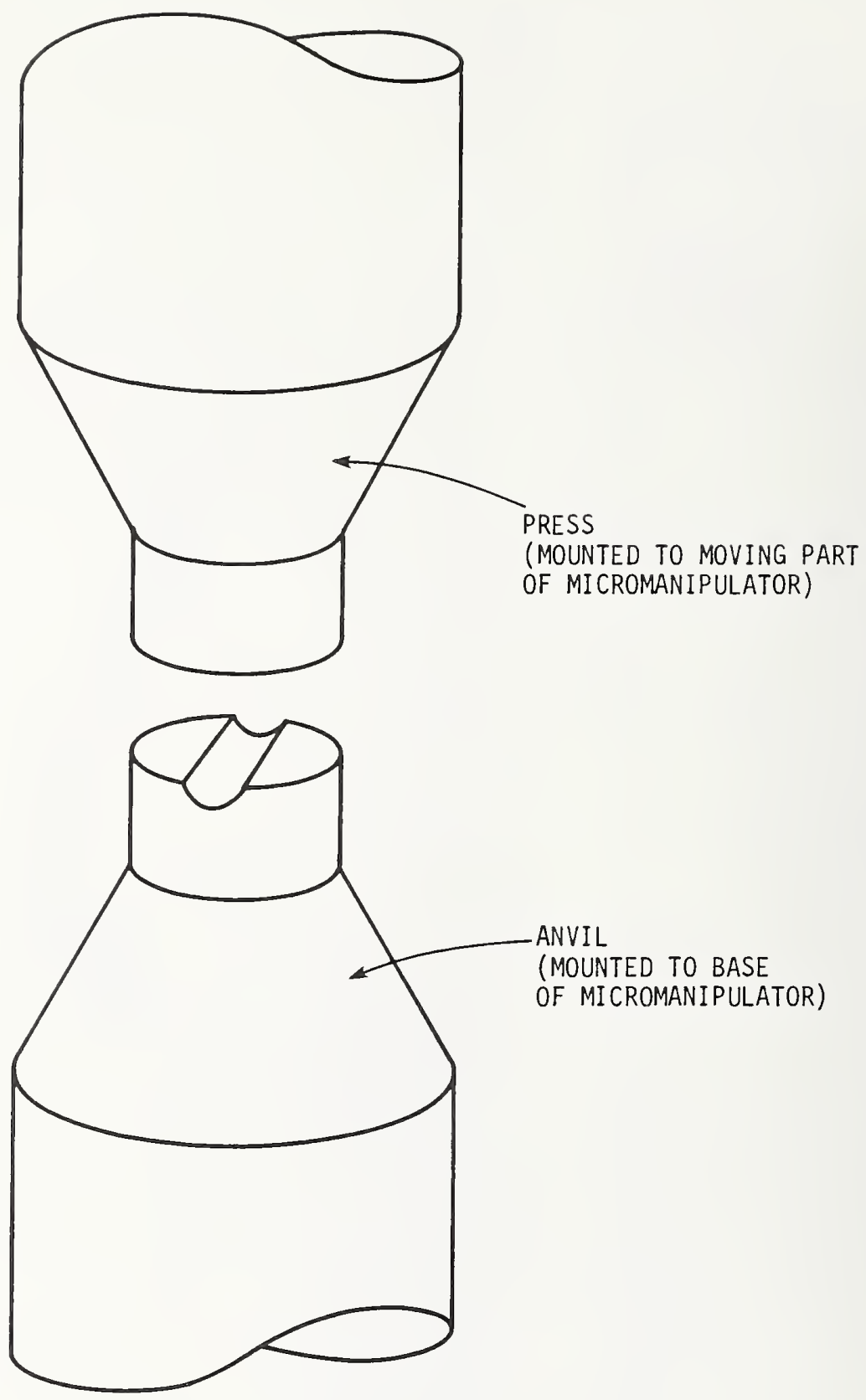

Figure 9. Press and anvil used to form "D"-shaped crimps. 


\subsection{Thermistor Placement}

The probe tube was trimmed about $0.5 \mathrm{~mm}$ beyond the ends of the crimps, the tube was gripped in a pin vise attached to a plastic block, and the block was located under a binocular microscope so that the ends of the crimps could be observed by looking directly into the probe tube. Using a sharp-pointed needle, a small amount of conductive epoxy glue was placed on each crimp. Next, a thermistor was picked up using a "vacuum pick-up" with a 27-guage hypodermic needle; and a short length of nylon monofilament thread held in a pin vise was used to paint a coating of quick-set epoxy glue in the area between the electrodes (to prevent the conductive epoxy glue from shorting the thermistor when it is placed). The hypodermic needle was then mounted on a micromanipulator so that the thermistor could be placed after the quick-set epoxy hardened. The hypodermic needle used had a hooked end so that the field of view would not be entirely obscured when the thermistor was lowered into place on the conductive epoxy drops. The end of the probe was then sealed with a small drop of epoxy.

\subsection{Connector Mounting}

Aside from the following two modifications, the usual mounting procedure for the connector $^{4}$ (see figure 5) was used: (1) The high resistance leads were crimped rather than soldered to the connector pins, and (2) a small brass ferrule was soldered to the shell of the connector.

Normally, the cable wires are inserted into tubular holes on the backside of the connector pins and soldered. The high-resistance leads cannot be soldered but it was found that the pins could be crimped sufficiently to grab the ends of the leads after they were inserted into the holes in the pins.

Normally, the braid of a shielded cable is soldered to the back end of the connector shel1. Instead, a small brass ferrule was soldered into this part of the connector (see figure 10 ).

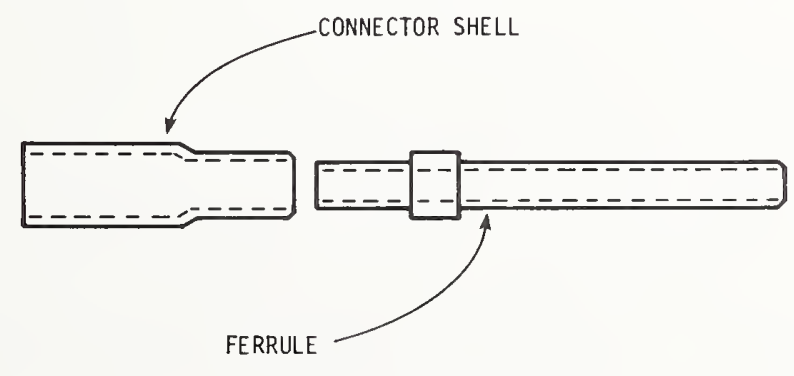

Figure 10. Extension ferrule for connector shell.

${ }^{4}$ The connector used, not necessarily an optimum choice, is a Model DP-4S-1, Microtech, Inc. 
The ferrule has two purposes. The high-resistance leads in conjunction with the surrounding metal tube form a "lossy line" type of filter, effectively preventing any rf pickup on the leads from reaching the probe cable. Also, the tube provides a greater gluing surface for securing the probe and connector together. (Note in figure 5 that a short length of heatshrink tubing has been shrunk over the brass ferrule and extends a short distance down the probe to act as a strain relief.)

\section{THERMOMETRIC TESTS}

The ensuing discussion describes tests done to evaluate the performance of the probes. Some further tests are described in section 5.

\subsection{Response Time}

The probe tip was plunged a few centimeters into still water that was approximately at room temperature and held stationary for 10 seconds. The 90-percent response time determined from a recording of the instrument output was approximately 1.3 seconds. Because a 90 percent response corresponds to about 2.3 time constants for exponential response (see section 4.3), the indicated time constant for the probe in still water is about 0.56 seconds.

No attempt was made to determine the probe-time constant for other media, but it seems reasonable to assume that the time constant for wet tissue, for instance, would not be much different than for still water because both the density and heat conductivity of wet tissue are roughly the same as for water.

\subsection{Sensitivity}

The ability of the probe and electronics system to measure short-term temperature variations is determined primarily by noise due to capacitively induced currents in the probe by nearby moving objects and noise generated by flexing movements of the probe and cable. Both of these noise sources vary greatly with the experimental arrangement. Connecting both the electronics common and the phantom or subject in which the probe is placed to the surrounding "ground" potential will usually achieve minimum noise, but this is not necessary if no nearby moving objects are present and if the probe and cable can be kept sti11. For example, curve 2 in figure 13 was recorded with the probe in simulated brain material ${ }^{5}$ that was not grounded. With reasonable care, temperature changes of a few

\footnotetext{
5 Relative dielectric constant $\varepsilon^{\prime} \approx 34$, loss tangent $\tan \delta \approx 0.44$, conductivity $\sigma \approx 0.77 \mathrm{~S} / \mathrm{m}$. (These values are for a frequency of $915 \mathrm{MHz}$ and are also approximately correct for $2000 \mathrm{MHz}$.)
} 
millidegrees can be sensed.

If the lead material of the probe is exposed to very strong electric fields, it is possible that another noise source could become significant. By some unknown mechanism, the high-resistance lead material generates electrical noise when strong electric fields at $r f$ frequencies induce significant currents on the leads. This type of noise was investigated by inserting the probe through holes in the sides of a piece of WR 430 waveguide with the thermistor extended well beyond the outside of the guide and the leads inside the guide parallel to the electric field. The exposed section of the probe was about $5 \mathrm{~cm}$. With the electric field in the guide (center) equivalent to that of a plane-wave field of $500 \mathrm{~mW} / \mathrm{cm}^{2}$, the extra noise was less than $0.02 \mathrm{C}$. The noise was more or less random and decreased roughly in proportion to the power level of the field.

\subsection{Measurement Artifacts}

In addition to the discussion in this section, measurement artifacts are the subject of section 5 . The thermographs presented in section 5 show that the probe is essentially nonperturbing, for the experimental conditions discussed there, within the approximately $0.2^{\circ} \mathrm{C}$ resolution of the thermographs. The experiments discussed below establish that the sources of possible temperature measurement artifact at the tip of the probe cause much less than $0.1{ }^{\circ} \mathrm{C}$ error when the probe is used in simulated brain material heated by $2 \mathrm{GHz}$ waves.

In section 2.1 it was shown that, for the design under discussion, the probe at distances far from the tip produces less heat than the volume of material displaced by the probe (except for relatively dry biological material such as bone or fat). At the tip of the probe, the electro-thermal conditions are difficult to analyze even qualitatively; but some simple and conclusive experiments can be performed to accurately measure any resulting artifacts. Essentially, the artifacts due to the tip of the probe can be measured by the probe itself.

As compared to a completely nonconductive but otherwise identical probe, any additional temperature (due to $\mathrm{rf}$ fields) indicated by the slightly conductive probe considered here would have to be due to whatever rf electric fields exist in the three lossy materials in the region near and including the tip. That is: (1) Heat generated directly in the resistive thermistor material, (2) heat generated in the lead material near the tip and conducted to the thermistor, and (3) extra heat generated in the lossy material outside the tip due to enhanced fields and conducted through the wall of the probe to the thermistor. Due to the very large surface-to-volume ratio of the region near the tip of the probe as compared to the full subject or model (necessarily much larger than the probe tip for proper operation of the probe), the time constant associated with the temperature rises caused by these sources of heat will be much less than that of the temperature rise of the subject or model. The time constant of (1), (2), and (3) will be less than or about the 
same as the time constant of the probe, i.e., roughly 1 second; whereas the time constant for the subject or model will normally be about 1 minute or more. Therefore, any significant additional temperature can be observed as a sudden rise in the indicated temperature as compared to the expected rise (eq (4), below) when rf energy is suddenly applied $[6,7] .^{6}$ This is a very important test because it is conclusive and is easily performed for most experimental arrangements.

Assuming that the heating rate in the material surrounding the tip of the probe is constant and that the thermistor heating rate is proportional to the difference between the thermistor temperature and the material temperature, it is easy to show that the thermistor temperature change $T$ is given by

$$
T=S t-S_{\tau}[1-\exp (-t / \tau)]
$$

where the material heating begins at time $t=0$ and $\tau$ is the time constant of the probe for the material. Figure 11 shows the thermistor response as predicted by eq (4) for a time

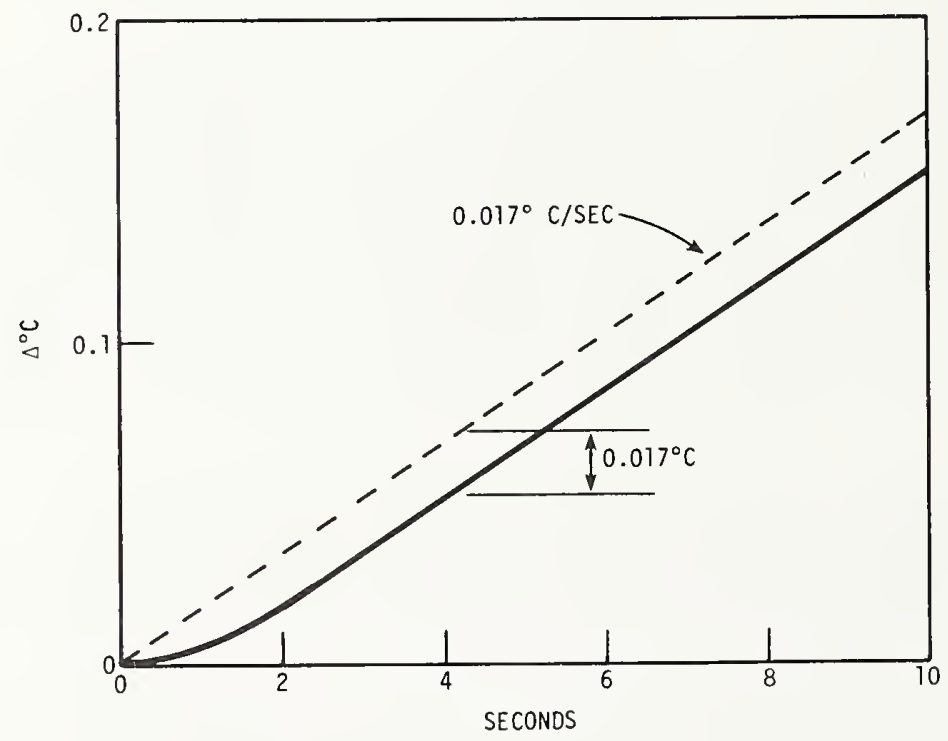

Figure 11. Theoretical response for a probe with a one second time constant to a one degree per second heating rate starting at $t=0$.

${ }^{6}$ If the electronics package is not well enough protected, $r f$ interference may cause a sudden increase (or decrease) in the indicated temperature that should not be confused with the temperature-caused artifacts under discussion here. 
constant of 1 second and a heating rate of $1^{\circ} \mathrm{C}$ per minute. For smal1 temperature rises, eq (4) should be fairly accurate and is a useful guide in predicting the response of the probe to initiation of constant heating.

Figure 12 shows the experimental arrangement used to test the probe for tip-related measurement artifacts. The probe was inserted parallel to the electric vector of the WR 430 guide fields, and the power level (at roughly $2 \mathrm{GHz}$ ) was adjusted to achieve a heating rate of about $1^{\circ} \mathrm{C}$ per minute when the simulated brain material was near room temperature. Curve 1 of figure 13 shows a recording of the indicated temperature for 20 seconds after the heating was initiated. From curve 1 , the heating rate was approximately $0.85 \mathrm{C}$ per minute.

Because the time constant of the probe for the simulated brain material was not measured, only an approximate predicted curve can be obtained from eq (4) to compare to the experimental curve. If, as seems reasonable, the time constant of the probe in the model is between $1 / 2$ second and 1 second, the eventual 1 ag predicted by eq (4) will be between 0.007 and $0.014^{\circ} \mathrm{C}$. Close scrutiny of curve 1 shows a lag of about $0.012^{\circ} \mathrm{C}$. Apparently, then, the net perturbing effects of the probe tip are no more than about $0.01{ }^{\circ} \mathrm{C}$, perhaps much less, for operation in the simulated tissue at $2 \mathrm{GHz}$.

\section{THERMOGRAPHIC TESTS}

Thermographic cameras can be used to observe the heating patterns in models and dead animals exposed to $r f$ fields $[8,9,10]$. By comparing thermographs made with and without electrodes implanted, distortions of the heating patterns due to the electrodes can be measured $[9,10]$. The following sections present thermographs taken to reveal any resolvable field-distortion effects of the temperature probe. ${ }^{7}$

\subsection{Experimental Arrangement and Procedure}

Figure 14 is a schematic of the experimental arrangement used to test the probe for perturbations of the heating patterns in a piece of simulated brain material.

This material was held in a hemispherical shape $(6 \mathrm{~cm}$ diameter) by a polystryene foam mold with the flat face covered with a thin fim of plastic to prevent drying of the material. For each test, this model was heated by a $915 \mathrm{MHz}$ diathermy applicator emitting 500 watts for either 15 seconds or 30 seconds. In all instances, the (incident) electricfield vector was parallel to the face of the model. Immediately before the applicator was turned on and immediately after it was turned off, a scan of the face of the model was made

${ }^{7}$ See acknowledgement. 


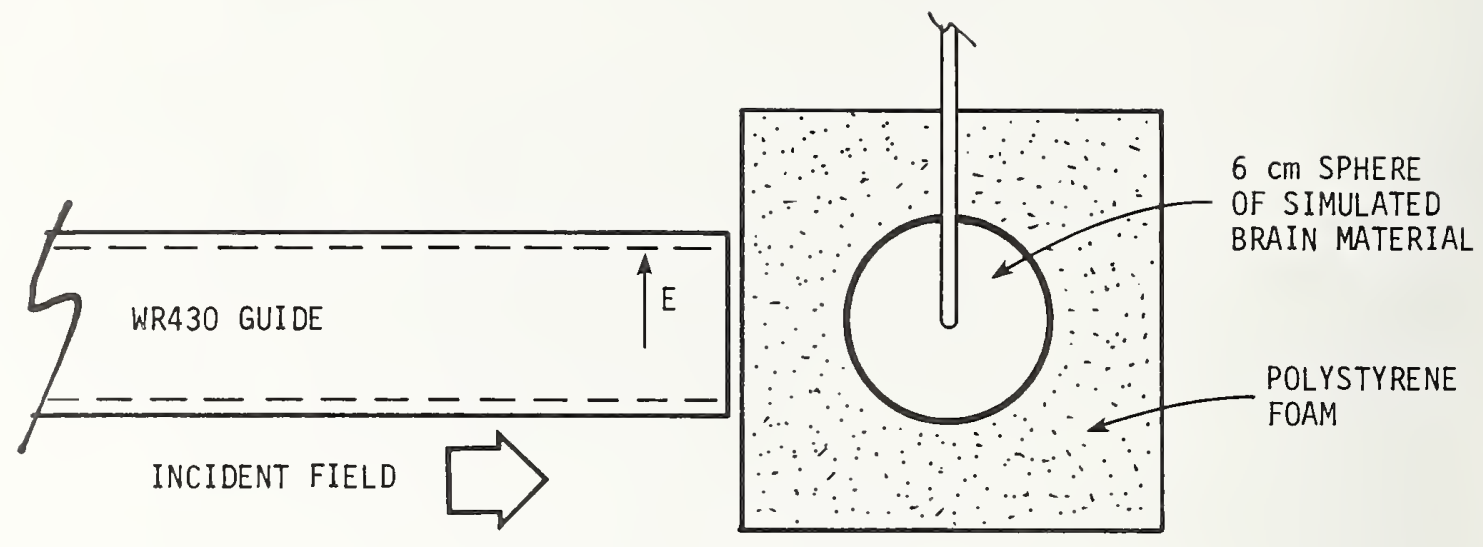

Figure 12. Model exposure arrangement for data of figure 13. The electric field polarization in the waveguide is parallel to the probe.

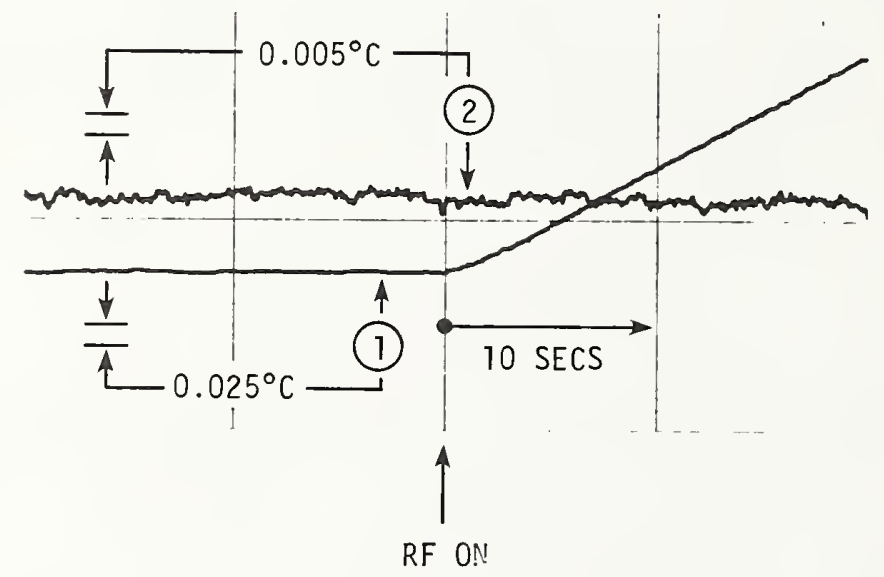

Figure 13. Curve 1 shows the response of the probe in the experimental arrangement of figure 12 to an initiation of RF heating.

Curve 2 (RF off) shows the noise level for this experimental arrangement. 
with the thermographic camera. When the probe was in place in the model, it was imbedded in the face of the model just under the plastic film.

Two scanning modes for the camera were used. In one mode the camera makes a single scan across the field of view, and the measured temperature at each point is displayed as an "X-Y" recording (see figures 15 and 16). The model was heated for 30 seconds for these scans. In the other mode, the camera scans the whole field of view line-by-line to produce an image of the temperature intensity pattern (see figure 17). The model was heated for 15 seconds for these scans.

\subsection{Single Scan of Probe Tip}

The orientation of the probe, model, and incident field for this test is shown in figure 15(a). Thermographs along the scan line before and after the model heating are also shown in this figure for the model with and without the probe imbedded. The location of the probe tip is indicated by the white arrow in the left-hand thermograph. Within the resolution of the thermographs, about $0.2 \mathrm{C}$, there is no perturbation due to the probe.

\subsection{Single Scan of Probe}

Referring to figure 16, it can be seen that for this test the incident electric-field vector was again parallel to the probe, but the scan line was along the probe. The tip of the probe is again indicated by the white arrow on the vertical center line in the left-hand thermograph.

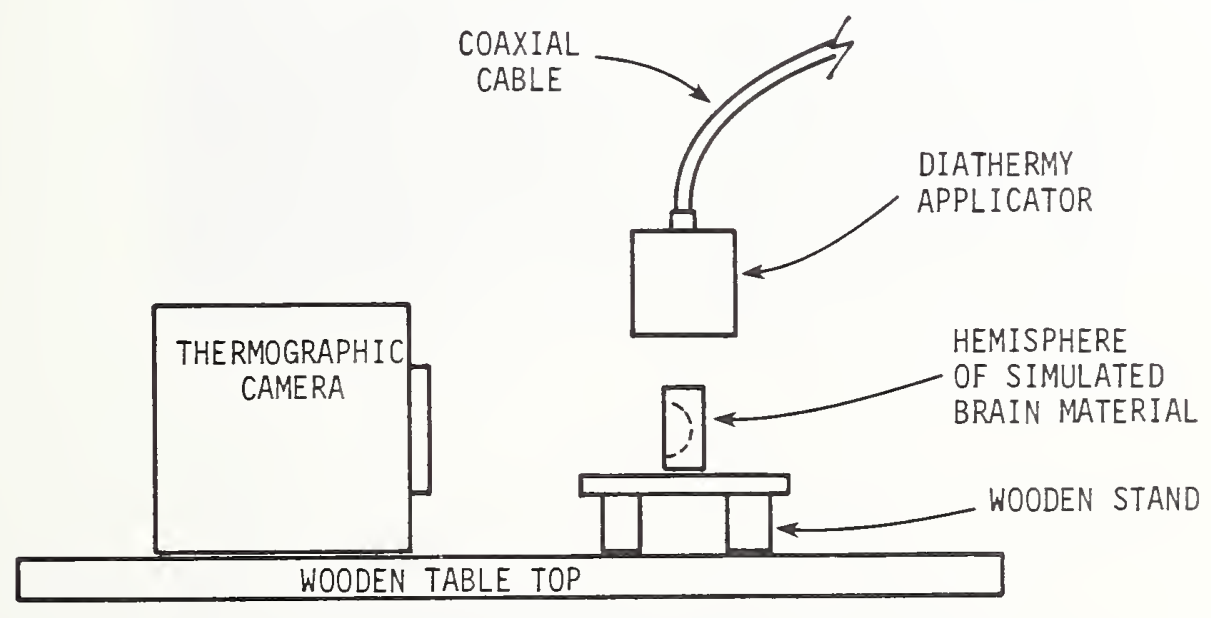

Figure 14. Experimental arrangement used for the thermographic recordings. 


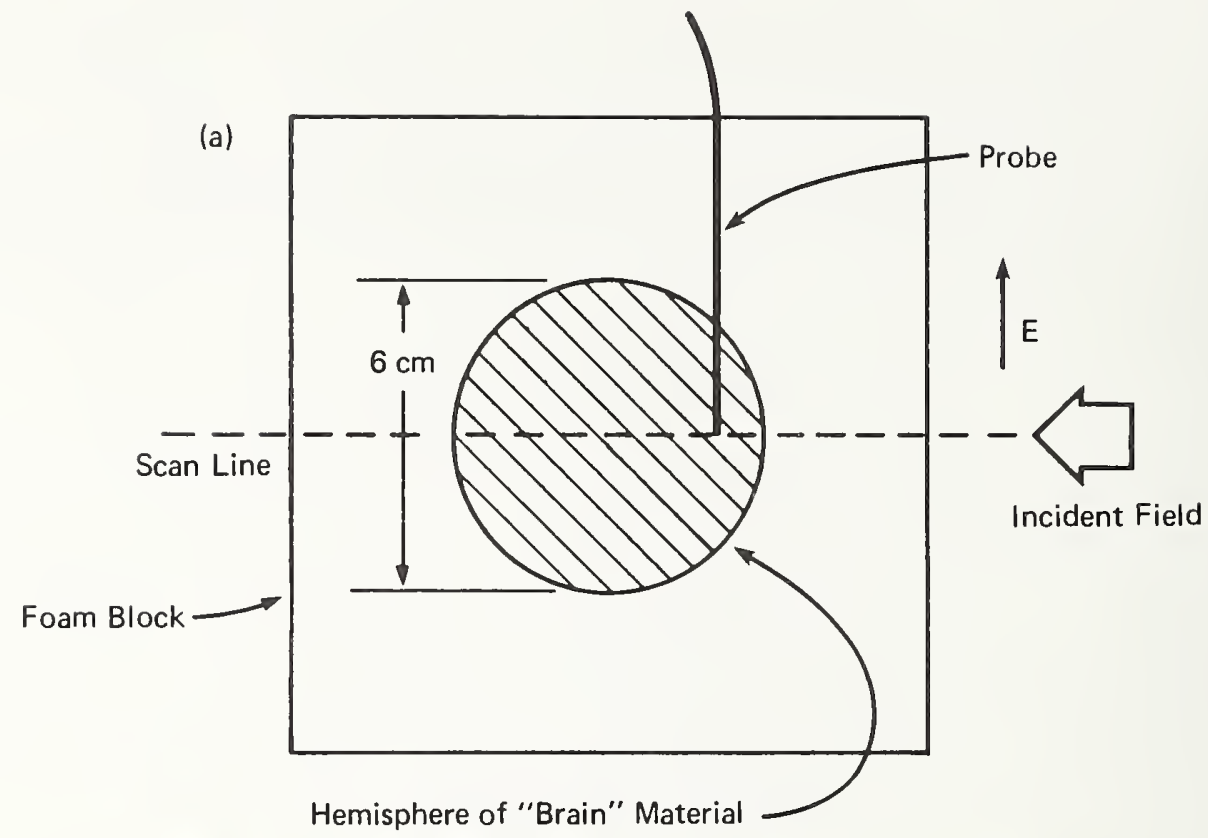

(b)
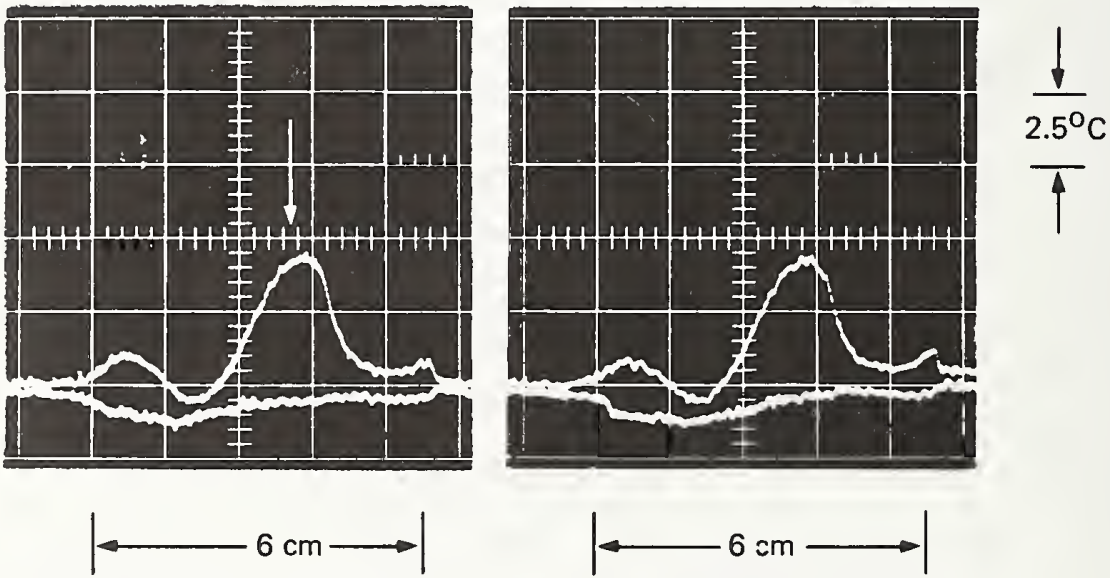

Figure 15. (a) Diagram showing model exposure geometry and thermographic scan line.

(b) Resulting thermographs. The position of the probe tip is indicated by the white arrow in the left-hand thermograph. The probe was removed for the right-hand thermograph. 


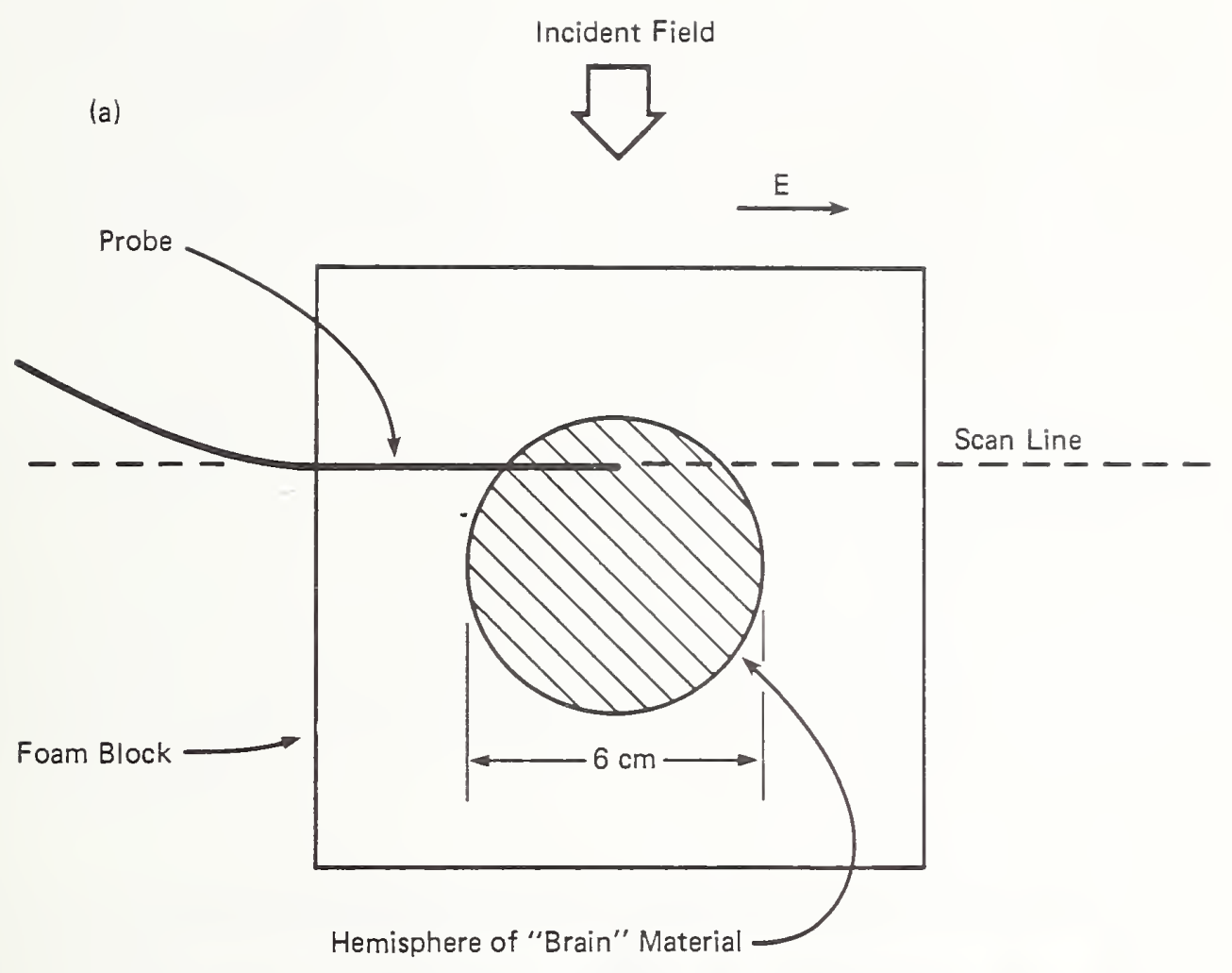

(b)

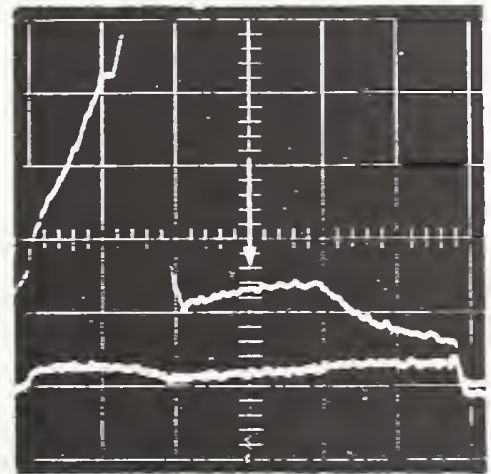

$\rightarrow 6 \mathrm{~cm}$
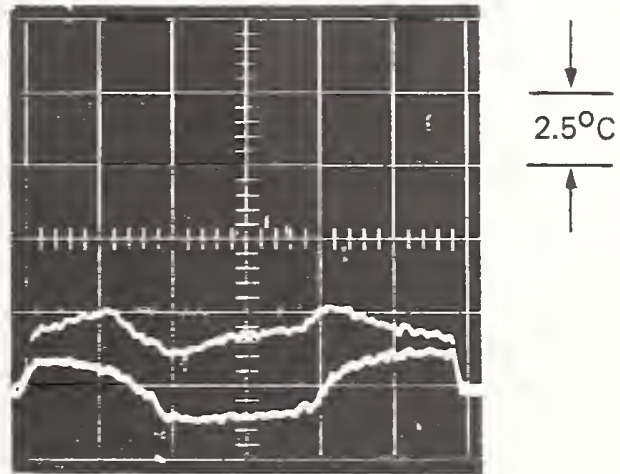

$\rightarrow 6 \mathrm{~cm} \mid=$

Figure 16.

(a) Diagram showing model exposure geometry and thermographic scan line.

(b) The position of the probe tip is indicated by the white arrow in the left-hand thermograph. The probe was removed for the right-hand thermograph. 
Some care must be exercised in interpreting the significance of figure 16 . There is no evidence of significant perturbation of the heating pattern within the simulated brain material, but outside this material the probe shows a rather large temperature rise. This is expected from the boundary conditions for electromagnetic fields: The tangential electric field and the normal displacement field are continuous across the boundary. Because, for experiments here, the incident electric field at the point where the probe enters is roughly normal to the surface, the field within the probe will be much greater for that portion just outside the model compared to that portion just inside. Even so, large temperature rises in the probe outside the model can only be achieved with high-power exposure and with worst-case alignment of the probe. For the experiments here, the applicator was emitting 500 watts and was only $12 \mathrm{~cm}$ from the probe. The probe survived this rather extreme situation without damage.

Note that the temperature just inside the model (2 $\mathrm{cm}$ left of the center line) has been only slightly perturbed by the probe despite the large temperature rise outside the model. This is due to the small diameter and low heat conductivity of the probe. The small perturbation just inside the model was easy to eliminate by the simple technique described in the next section.

For high-power exposure, parallel alignment of the probe with the external field should not be used because additional noise may be generated (see section 4.2). For most situations, it is easy to avoid the worst-case alignment of the probe, and this is recommended practice.

\subsection{Image Scan of the Model}

Figure 17 shows the results of image scans made for the same probe, model, and field orientation used for the scans of figure 16. The experimental arrangement was, however,
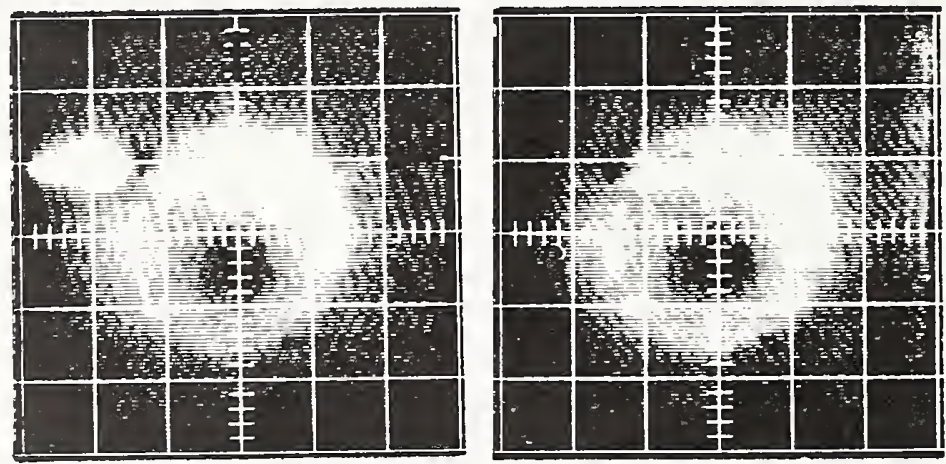

Figure 17. Thermographic images of the model resulting from the exposure geometry shown in figure 16. The position of the probe tip is indicated by the black arrows in the left-hand image. The probe was removed for recording the right-hand image. 
different in one way. A small piece (roughly $1 / 4 \mathrm{~cm}^{3}$ ) of high-dielectric constant material was molded around the probe where it entered the model. (This material was in the form of a putty made from silicon grease and a high-dielectric constant ceramic power; however, a small piece of wet sponge would have worked just as well.) As a result, the slight heating at the surface caused by the temperature rise on the "unprotected" portion of the probe occurs in the high-dielectric piece rather than in the model, as clearly shown in figure 17.

\section{CONCLUSION}

The probe described in this paper has been shown to be very effective for measuring temperature in biological materials, or materials that simulate biological matter, that are being heated by $r$ energy. The probe allows the small size, stability, and sensitivity of the thermistor to be utilized for electromagnetic bioeffects research, electrothermia therapy, and perhaps in some industrial situations. Compared to other possibilities for such measurements, this type of probe requires relatively simple electronics that are easy to use, calibrate, and maintain.

The main deficiency of the probe is that it is very difficult to fabricate, at least for the small diameter version discussed herein. Another deficiency is that it is more difficult to achieve a long nonperturbing length (say 1 meter or more) with this type of probe than it is for a probe using optical fibers for information transmission. A further deficiency, for some experimental situations, is that the probe could cause some excess heating if used in materials, such as fat or bone, with relatively low water content.

\section{ACKNOWLEDGMENT}

The thermographic tests were performed at the University of Washington, Seattle, Washington. The author is indebted to Arthur W. Guy, Professor and Director, Bioelectromagnetics Research Laboratory, for the use of his laboratory and equipment. Many thanks are also due staff member John A. McDougal who constructed the models and made the thermographs shown in this report. 


\section{REFERENCES}

[1] Rozze11, T. C., Johnson, C. C., Durney, C. H., Lords, J. L., and 01son, R. G., A nonperturbing temperature sensor for measurements in electromagnetic fields, J. Microwave Power $\underline{9}$ (Sept. 1974).

[2] Cetas, T. C., A birefringent crystal optical thermometer for measurement of electromagnetically induced heating, Biological Effects of Electromagnetic Waves, HEW Pub1. (FDA) 77-8011, Vo1. II, 338 (1976).

[3] Deficis, A., and Priou, A., Non-perturbing microprobes for measurement in electromagnetic fields, Microwave J. 20, No. 4, 55 (April 1977).

[4] Christensen, D. A., A fiber-optic probe with semiconductor sensor for temperature measurements in electromagnetic fields, Presented at the 1977 International Symposium on the Biological Effects of Electromagnetic Waves, Airlie, Virginia.

[5] Chen, M. M., Cain, C. A., Mullin, J., and Loh, K., Viscometric thermometer: An instrument for temperature measurement in EM fields, Presented at the 1977

International Symposium on the Biological Effects of Electromagnetic Waves, Airlie, Virginia.

[6] Larsen, L. E., Moore, R. A., and Acevedo, J., A microwave decoupled brain-temperature transducer, IEEE Trans. Microwave Theory Tech. MTT-22, 438-444 (Apri1 1974).

[7] Bowman, R. R., A probe for measuring temperature in radio-frequency heated material, IEEE Trans. Microwave Theory Tech. MTT-24, 43 (1976).

[8] Guy, A. W., Analyses of electromagnetic fields induced in biological tissues by thermographic studies on equivalent phantom models, IEEE Trans. Microwave Theory Tech. MTT-19, No. 2, 205-214 (Feb. 1971).

[9] Johnson, C. C., and Guy, A. W., Nonionizing electromagnetic wave effects in biological materials and systems, Proc. IEEE 60 No. 6, 692-718 (1972).

[10] Guy, A. W., Engineering considerations and measurements, AGARD Lecture Series No. 78 (on Radiation Hazards), AGARD-LS-78 (1975). 
NRS. 114A (REV. 9-78)

\begin{tabular}{|c|c|c|c|}
\hline $\begin{array}{l}\text { U.S. DEPT. OF COMM. } \\
\text { BIBLIOGRAPHIC DATA } \\
\text { SHEET }\end{array}$ & $\begin{array}{l}\text { 1. PUBLICATION OR REPORT NO. } \\
\text { NBSIR } 80-1634\end{array}$ & 2.Gov't. Accession No. & 3. Recipionts $4 c$ cession 10 . \\
\hline \multirow{2}{*}{\multicolumn{3}{|c|}{ A Temperature Probe for Radio-Frequency Heated Material }} & $\begin{array}{l}\text { 5. Publication Date } \\
\text { January } 1981\end{array}$ \\
\hline & & & 6. Performing Organization Code \\
\hline \multicolumn{3}{|l|}{$\begin{array}{l}\text { 7. AUTHOR(S) } \\
\text { Ronald R. Bowman }\end{array}$} & 8. Performing Organ. Report No. \\
\hline \multicolumn{3}{|c|}{$\begin{array}{l}\text { 9. PERFORMING ORGANIZATION NAME AND ADDRESS } \\
\text { NATIONAL BUREAU OF STANDARDS } \\
\text { DEPARTMENT OF COMMERCE } \\
\text { WASHINGTON, DC } 20234\end{array}$} & 10. Project/Task/Work Unit No. \\
\hline \multirow{2}{*}{\multicolumn{3}{|c|}{$\begin{array}{l}\text { 12. SPONSORING ORGANIZATION NAME AND COMPLETE'ADDRESS (Street, City, State, ZIP) } \\
\text { Same as item } 9 .\end{array}$}} & 13. Type of Report \& Period Covered \\
\hline & & & 14. Sponsoring Agency Code \\
\hline
\end{tabular}

15. SUPPLEMENTARY NOTES

Document describes a computer program; SF-185, FIPS Software Summary, is attached.

16. ABSTRACT (A 200-word or less factual summary of most significant information. If document includes a significant bibliography or literature survey, mention it here.)

One approach to measuring temperature in radio-frequency (rf) heated material employs thermocouple or thermistor sensors connected to suitable electronics by means of leads of such slight conductivity that they cause negligible field distortion and measurement artifacts. The particular type of probe discussed here uses a thermistor. Four leads are used to allow the thermistor resistance to be sensed despite the large and unstable lead resistances. Though difficult to construct, small probes (about $1.1 \mathrm{~mm}$ in diameter) for use in biological tissue can be made that cause measurement artifacts so slight (about $0.01^{\circ} \mathrm{C}$ or less) that they are difficult to measure. Theory and experimental results are presented to show that these probes are very effective for use in materials with high water content. In most situations of interest, the short term stability is better than $0.01^{\circ} \mathrm{C}$, and the long term stability is about $0.1^{\circ} \mathrm{C}$.

17. KEY WORDS (six to twelve entries; alphabetical order; capitalize only the first letter of the first key word unless a proper name; separeted by semicolons)

Heating; probe; radio-frequency; temperature measurements.

18. AVAILABILITY $\quad X$ Unlimited

For Official Distribution. Do ilot Release to NTIS

Order From Sup. of Doc., U.S. Government Printing Office, Wasinington, DC 20402, SD Stock No. SNO03-003-

X Order From National Technical Information Service (NTIS), Springfield, VA. 22161

\begin{tabular}{|l|c|}
\hline $\begin{array}{l}\text { 19. SECURITY CLASS } \\
\text { (THIS REPORT) } \\
\text { UNCLASSIFIED }\end{array}$ & 36 \\
\hline $\begin{array}{l}\text { 20. SECURITY CLASS } \\
\text { (THIS PAGE) }\end{array}$ & 22. Price \\
PRINTED PAGES & $\$ 6.00$ \\
\hline
\end{tabular}

is U.S. GOVERNMENT PRINTING OFFICE: 1981-778.913/246 Region No. 8 



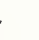





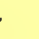


